\title{
TECHNOLOGY AND EQUIPMENT FOR RESISTANCE BUTT WELDING OF LARGE-SECTION PARTS OF DISSIMILAR STEELS
}

\author{
S.I. KUCHUK-YATSENKO, A.A. NAKONECHNY, \\ I.V. ZYAKHOR, S.V. CHERNOBAJ and M.S. ZAVERTANNY \\ E.O. Paton Electric Welding Institute, NASU \\ 11 Kazimir Malevich Str., 03680, Kiev, Ukraine. E-mail: office@paton.kiev.ua
}

\begin{abstract}
The resistance butt welding finds new areas of application. The aim of the work is the development of technology for RBW of T-joints of rods and eyelets of hydraulic cylinders of dissimilar steels 45 and 17GS in the range of diameters from 16 to $60 \mathrm{~mm}$. The tasks of investigations were the selection of optimal technological scheme of RBW process of large cross-section parts, testing of technological methods, providing localization of heating and deformation of metal in the contact zone. The RBW process and the structure of joints of these dissimilar steels produced with preliminary preparation of welded edges and using the composite inserts were investigated. It was found that in RBW of T-joints of steels 45 and 17GS with optimum preparation of welded edges and programmable change in welding force at the stage of heating it is succeeded to localize the heat generation in welding zone, to avoid the formation of defects and to provide the high mechanical properties of welded joints. During mechanical tests of welded rods on bending the fracture occurs in the base metal of the rod. The technology for RBW of T-joints of dissimilar steels using the composite inserts was developed. The technology of RBW of rods of hydraulic cylinders of 16-60 mm diameter was realized in specialized welding machine K1040, designed and manufactured at the PWI. 14 Ref., 15 Figures.
\end{abstract}

Keywords : resistance butt welding, T-joint, hydraulic cylinder rod, dissimilar steels, welded joint, preparation of edges, composite insert

For the domestic machine building the actual problem is the development and implementation of an effective high-performance technology for welding the rods of hydraulic cylinders. The billets of a rod of high-strength steel 45 of 16-60 mm diameter should be joined with the eyelets of steel 17GS of 20 $200 \mathrm{~mm}$ diameter with wall thickness of 5-24 mm. A significant volume of production of welded rods of hydraulic cylinders causes a necessity of applying the high-performance technology and equipment providing operations on clamping, alignment, welding, as well as, in some cases, heat treatment of products in automatic or semi-automatic mode.

At the present time in different fields of industry the high-performance methods of pressure welding are used, in particular, friction welding and resistance butt welding. Friction welding meets the majority of the abovementioned requirements, but a rather high cost of the modern equipment is a limiting factor in its use in the domestic machine building.

The carried out analysis showed that from the standpoint of technical and economic efficiency of solving the problem of welding rods of hydraulic cylinders, the application of RBW is the most appropriate. This method is widely used in the industry for dissimilar joint of metal cutting tool, band saws, wires, bars, tubes of steel and non-ferrous metals [1-3]. The RBW found a wide spreading due to a high performance, hygiene of the process, acceptable cost of the equipment necessary for its realization. In welding of high-strength aluminum alloys [4], advanced structural materials, in particular alloys based on titanium aluminides [5, 6] and powder materials [7] the RBW using the intermediate layers is challenging.

However, for the traditional RBW technology some disadvantages are inherent, in particular, decrease in mechanical properties of the joints, especially ductility values $[1,8]$ which is connected with overheating of metal, formation of coarse-grained structure in the joint area and defects in the form of oxide films and microcracks. To a large extent it is revealed in welding of large-section parts. The problem of providing a stable high quality of welded joints during RBW of large-section products of high-strength steels is relevant over many years.

The aim of the work is the development of technology for RBW of T-joints of rods and eyelets of hydraulic cylinders of dissimilar steels 45 and $17 \mathrm{GS}$ in the range of diameters from $16 \mathrm{~mm}$ to $60 \mathrm{~mm}$.

The rods of hydraulic cylinders are manufactured of carbon steel 45 which has the following values in as-delivered state: $\sigma_{\mathrm{t}}=590 \mathrm{MPa}, \mathrm{HB} 2100 \mathrm{MPa}$, the 


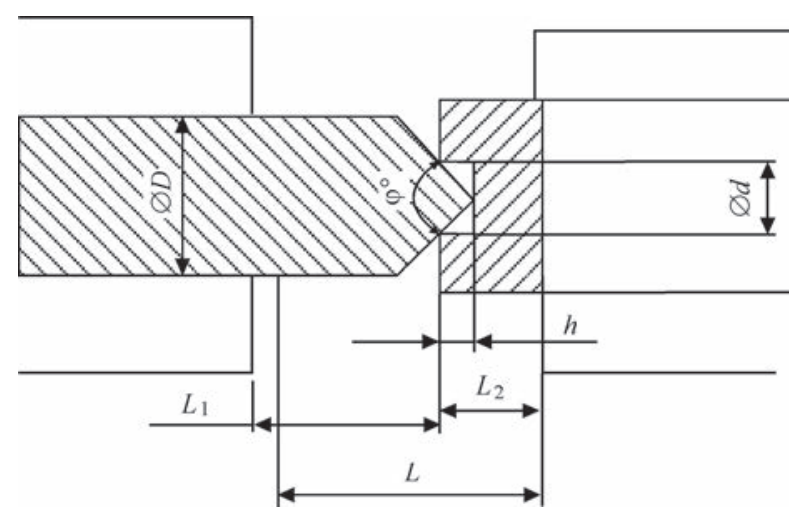

Figure 1. Scheme of preliminary preparation of edges of rod and eyelets for RBW

surface of the rod is coated with chromium of $0.15 \mathrm{~mm}$ thickness. The eyelet is manufactured by grinding of steel $17 \mathrm{GS}$, in as-delivered state it has $\sigma_{\mathrm{t}}=510 \mathrm{MPa}$ and $H B 1800 \mathrm{MPa}$.

During the experiments, welding machine K1040 was used, designed and manufactured at the PWI. Machine K1040 provides the realization of RBW process with continuous or step change in welding force in the range from 600 to $7200 \mathrm{~kg}$. The control system of the machine on the basis of KSU KS02 provides automatic cycle of welding and heat treatment, quality control and registration of welding parameters, as well as control of the frequency converter. In RBW of large-section parts the significant loads to electrical mains with a pulsed increase in current prevail. Therefore, three-phase-one-phase converter [9] was used, providing a uniform three-phase loading of mains.

The initial requirements during the development of technology for RBW of T-joints of rods of hydraulic cylinders were providing the formation of defect-free joints with mechanical properties being at the level of the base metal values, keeping the preset allowances
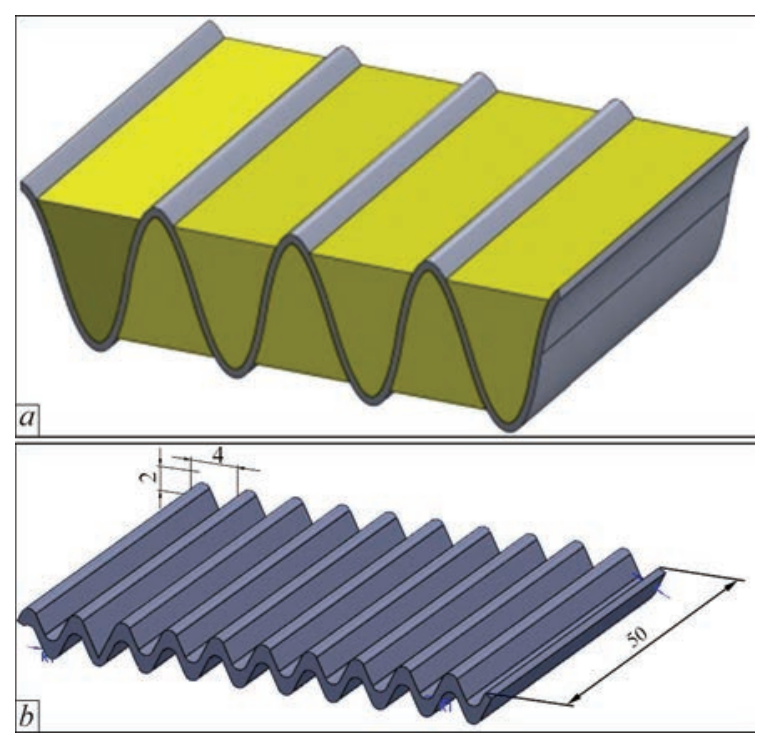

Figure 2. Scheme of CI with activating flux $(a)$ and metallic profiled insert $(b)$ for dimensions of the product. It is known that a high quality of joints during RBW is provided at high current densities, minimum heating period, current and pressure cycles (continuous or step), corresponding to a particular section of billets, increased allowances for upsetting $[1,3]$. In this case, the formation of a coarse-grained structure is excluded and the removal of contaminants, oxide phases and overheated metal from the welding zone is provided.

For the RBW process of T-joints of dissimilar steels the significant differences in the conditions of heating of part metal volumes adjacent to the butt are typical, which causes the asymmetry of deformation conditions and complicates the ejection of oxide films from the butt and formation of quality joints. Therefore, during development of technology for RBW of rods of hydraulic cylinders the tasks were put to find the ways of localization of processes of heating and deformation of the metal in the contact area and improvement of efficiency of dispersing, dissolving of oxide phases and their ejection from the butt.

While practicing the technology of welding the rods of hydraulic cylinders the following technological schemes were investigated: RBW with preliminary preparation of welded edges - scheme 1 (Figure 1), and RBW using the composite inserts (CI) - scheme 2 [10] (Figures 2 and 3). It was assumed that the preliminary edge preparation and the use of CI would allow expanding the technological capabilities of the process of RBW of large-section billets in producing dissimilar joints of structural steels.

CI (see Figure 2) consists of a metal base and a flux [10] the composition of which is preset so that its melting temperature $T_{\text {melt.f }}$ is below the melting temperature of the base metal $T_{\text {melt.BM }}$ of parts being welded. The presence of flux allows protecting the metal heated at the contact zone from oxidation and provides quality joints formation in the process of upsetting of parts. Thus, the possibility of producing joints at the heating temperature of metal of near-contact layers below the solidus temperature of the base met$\mathrm{al}$, and to form the joints a lower deformation of ends is required than that in traditional RBW technology.

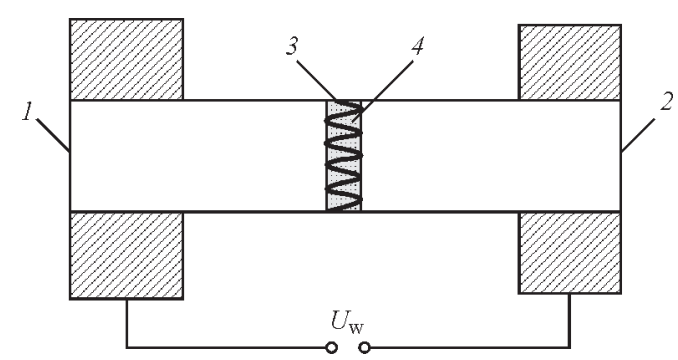

Figure 3. Scheme of RBW process using CI: 1, 2 - parts; 3 - CI with flux 
The base of CI consists of a profiled sheet (Figure 2, $b$ ), height and pitch of the profile are selected from the calculation of admissible current density and define the intensity of heat generation in the contact. The shape of CI relief influences the intensity of heat generation in the contact area, especially at the initial stage of heating, and the formation of welded joint. The increase in the concentration of heat generation in the contact area is determined by a high current density. The parameters of metal profiled insert were changed in the following range: sheet thickness 0.8 $2.0 \mathrm{~mm}$, profile pitch $2-4 \mathrm{~mm}$, and height of peaks was $1-2 \mathrm{~mm}$.

The composition of welding flux is one of the determining factors of RBW technology using CI. The flux protects the welding area from the atmosphere, acts as a heat source in the contact area of parts, cleans the metal surface from oxide films and facilitates the spreading the molten metal over the surface. Moreover, the flux deoxidizes the metal in parts contact and influences crumpling of the profiled insert. To provide a high quality of welded joint, properties of flux should meet the following requirements: react with oxides before the formation of liquid metal phase, wet the metal of parts being welded and the metal of insert, not to cause corrosive effect on the joined parts, not to change its chemical composition during heating due to evaporation of separate components.

In the work the oxide-salt fluxes of $\mathrm{Na}_{2} \mathrm{~B}_{2} \mathrm{O}_{7}-$ $\mathrm{Li}_{3} \mathrm{AlF}_{6}-\mathrm{TiO}-\mathrm{KF}$ system and the salt flux of $\mathrm{Na}_{2} \mathrm{~B}_{2} \mathrm{O}_{7}-\mathrm{CaF}_{2}-\mathrm{BaF}_{2}-\mathrm{LiF}$ system were used. The flux was applied in the form of alcohol slurry on the surface of the profiled insert. In the composition of flux as a binder $5 \%$ of nitrovarnishes was added, which prevented shedding of the flux after drying from the profiled insert surface. To form the liquid phase, wetting surfaces of parts being welded and ejection of fluxing remnants from the butt, the depressant elements were included into flux composition, which come into reaction of contact melting with the metal of parts and the profiled insert. In welding of carbon and low-alloy steels these elements are carbon and manganese, which are introduced into the composition of flux in the amount of 15 and $10 \%$, respectively. This allows producing a liquid metal phase already at $1150{ }^{\circ} \mathrm{C}$.

At the initial stage of the RBW process, welding flux prevents crumpling of the relief of the profiled metal insert. When electric current passes through the butt with CI (see Figure 3), the intensive heating and melting of the insert is observed due to a significant internal resistance. This is accompanied by localization of heating as compared to the traditional method of resistance heating. The value of transition resis-

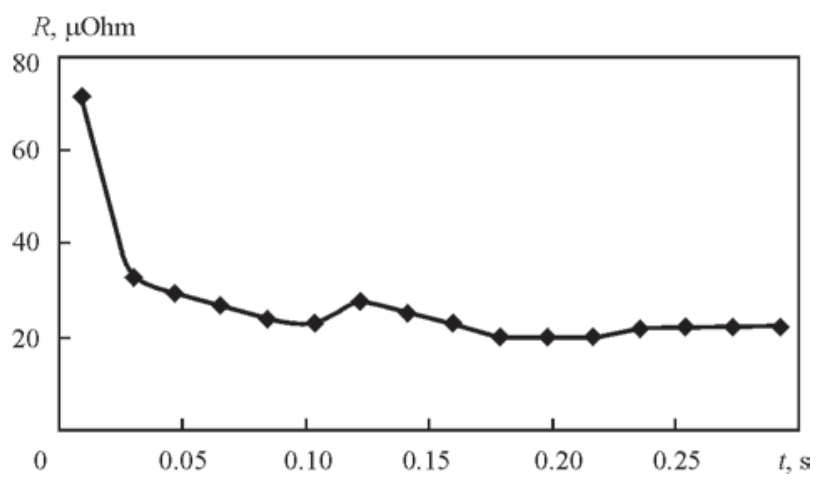

Figure 4. Time change of complete resistance in contact zone during RBW of steels 45 to $17 \mathrm{GS}$ specimens with $d=32 \mathrm{~mm}$

tance in the contact area then decreases (Figure 4), that is correlated with the data of work [11].

The selection of cyclogram of changes of RBW parameters was carried out on the basis of literature data $[1,3]$, results of previous investigations of the authors [12] and technical capabilities of welding equipment. In welding machine K1040 the clamping forces are provided by a four-section pneumatic cylinder, that allows realizing the required cyclogram of RBW process by switching the pneumatic valves of each section, controlled by a microprocessor (Figure 5).

The first series of experiments on RBW of rods of hydraulic cylinders of steels $17 \mathrm{GS}$ and 45 was carried out with the use of preliminary edge preparation according to scheme 1 (see Figure 1). The parameters of edge preparation were optimized so that the initial contact was near the apex of the cone and the bottom of the groove, and the total allowance for welding was preset depending on the diameter of the billets so that during plastic deformation of billets the remnants of cast metal, oxide films were ejected beyond the welded joint.

The formation of joints during RBW was investigated according to scheme 1 . Such a scheme is recommended [13,14] for welding of T-joints and is called «welding on the sharp edge». The carried out

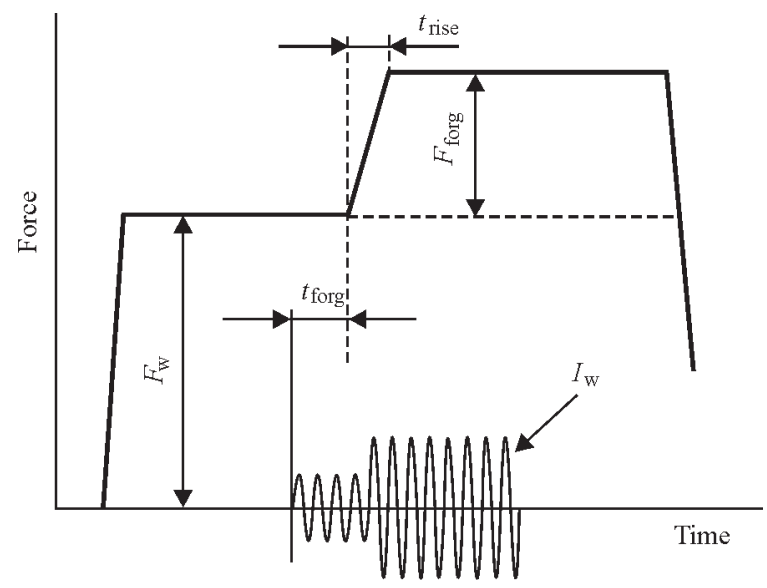

Figure 5. Cyclogram of RBW process with programmable change in welding force 


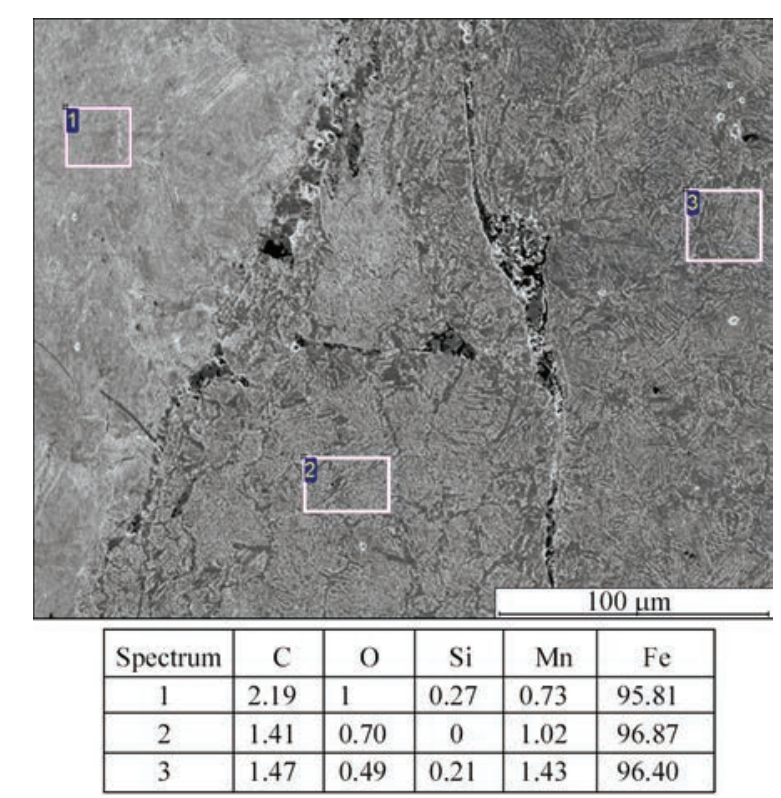

Figure 6. Microstructure of steels 45 to $17 \mathrm{GS}$ welded joint produced according to scheme 1 in Figure 1 at single-stage cyclogram of force

investigations found that RBW with a single-stage cyclogram of welding force application cannot localize heat generation in the welding area, the remnants of molten metal are found in the butt, and the defects are formed as a result of air pressing-in into the joint (Figure 6). Therefore, the further experiments on RBW were carried out with programmable change in welding force in accordance with the cyclogram presented in Figure 5, and an optimized shape of edge preparation, excluding air pressing-in into the joint zone.

The macrostructure of welded joint of rod with eyelet produced using RBW according to scheme 1 is presented in Figure 7, and the microstructure of metal in different zones of the joint - in Figures 8-10. The optical microscopy and SEM found that in the joining area in different parts of the section, namely central (Figure 8), middle (Figure 9) and peripheral (Figure 10), lacks of penetration, oxide films, cracks

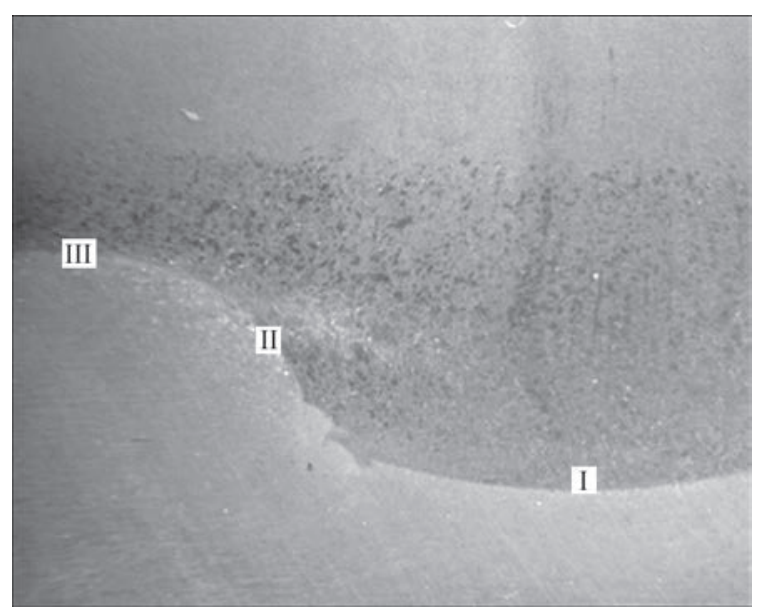

Figure 7. Macrostructure $(\times 4)$ of steels 45 to $17 \mathrm{GS}$ welded joint (for I-III see Figures 8-10, respectively)

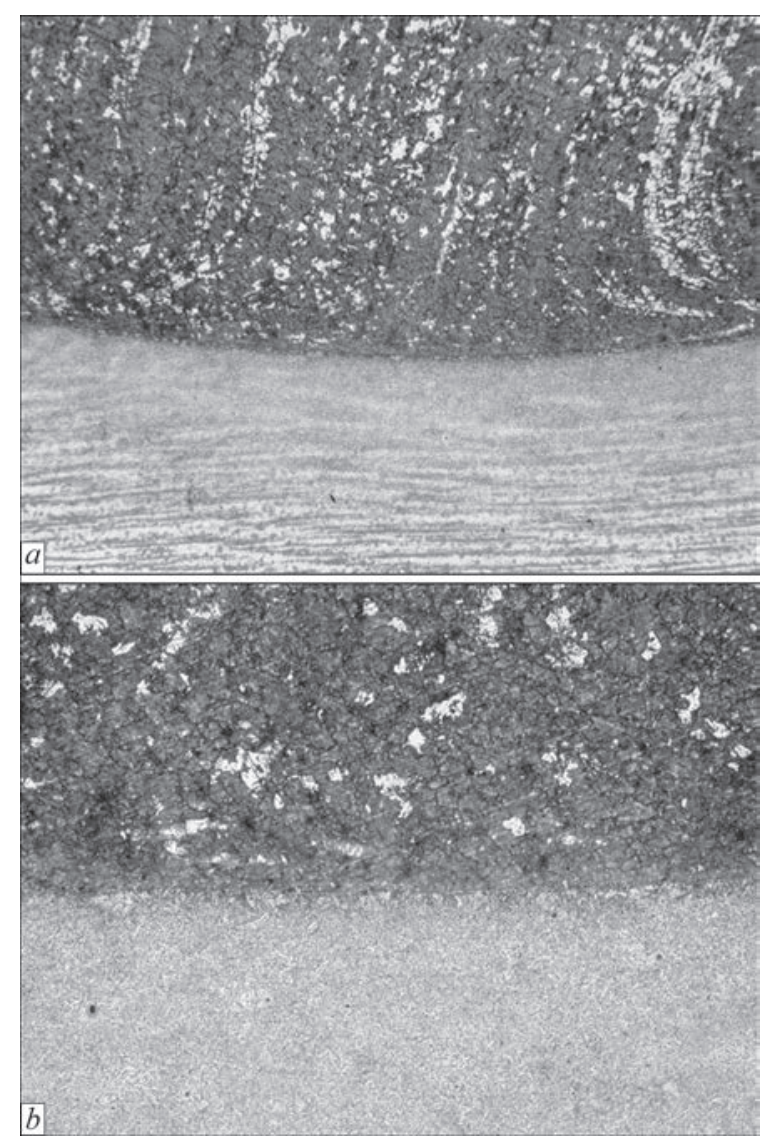

Figure 8. Microstructure of metal of central area I: $a-\times 25 ; b-$ $\times 100$

caused by the formation of hardening structures are absent. The absence of areas with cast and coarsegrained structure at the boundary, characteristic for overheated metal, evidences that the process of metal solidification in the joining area occurred under the conditions of intense shear deformation during upsetting. The structure in the joint zone and zone of thermomechanical influence is ferrite-pearlite, the areas with martensite structure were not revealed.

It is known that the rate of deformation has a significant influence on the structure and properties of metal of welded billets, namely during its increase a more fine-grained structure is formed in the joining area. This is explained by the fact that solidification process is suppressed by the deformation process, accompanied by refining of grains. Therefore, in the pressure welding methods it is recommended to apply the scheme of comprehensive uneven compression, which allows controlling the volumetric stressed state and character of plastic deformation.

At the developed optimal RBW modes according to scheme 1 the deformation of metal occurs under the conditions of comprehensive non-uniform compression and has a character of viscous flow (the same as during extrusion), which contributes to gripping of welded surfaces, their cleaning from oxide films, «healing» of micro-discontinuities and structural re- 


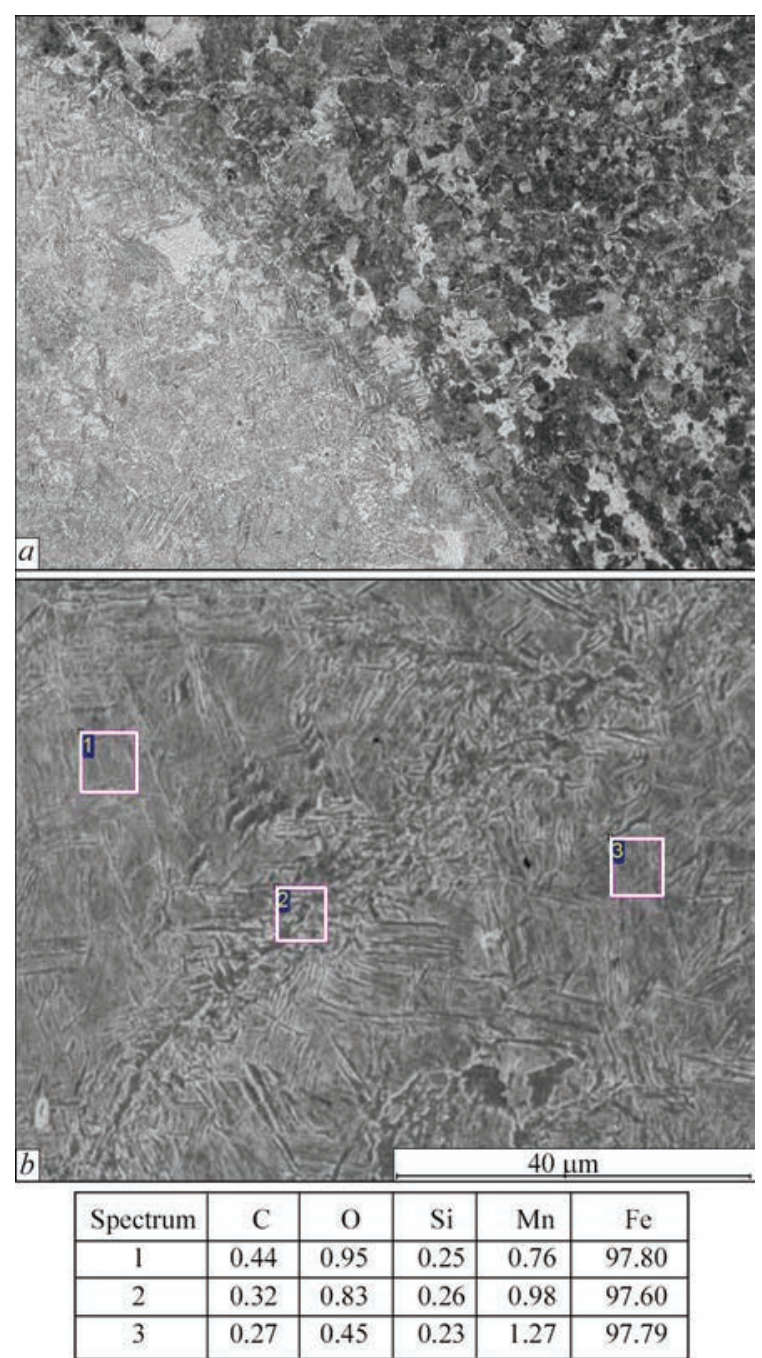

Figure 9. Microstructure of metal of middle area II: $a-\times 100$; $b-\mathrm{SEM}$

finement. At the end of upsetting a large part of metal, heated till switching off the power, is squeezed beyond the welded section, and in the joining area the metal is remained which was not subjected to heating up to high temperatures.

The mechanical tests of welded rods on bending in the welding zone were carried out in hydraulic press with maximum $100 \mathrm{t}$ force. The welded rod was considered qualitative under the conditions of fracture outside the zone of welded joint. Figure 11, $a$ presents the welded rod after the tests: localization of fracture occurs along the base metal. Thus, in RBW with optimal preparation of welded edges and programmable change in welding force at the stage of heating it becomes possible to localize heat generation in the welding zone, to avoid defects formation in the joints of rods in the investigated range of diameters and to provide high mechanical characteristics of welded products.

The RB-welded rod produced according to scheme 2 with the use of CI of steel 09G2S with the activating flux is presented in Figure 11, $b$. The microstructure
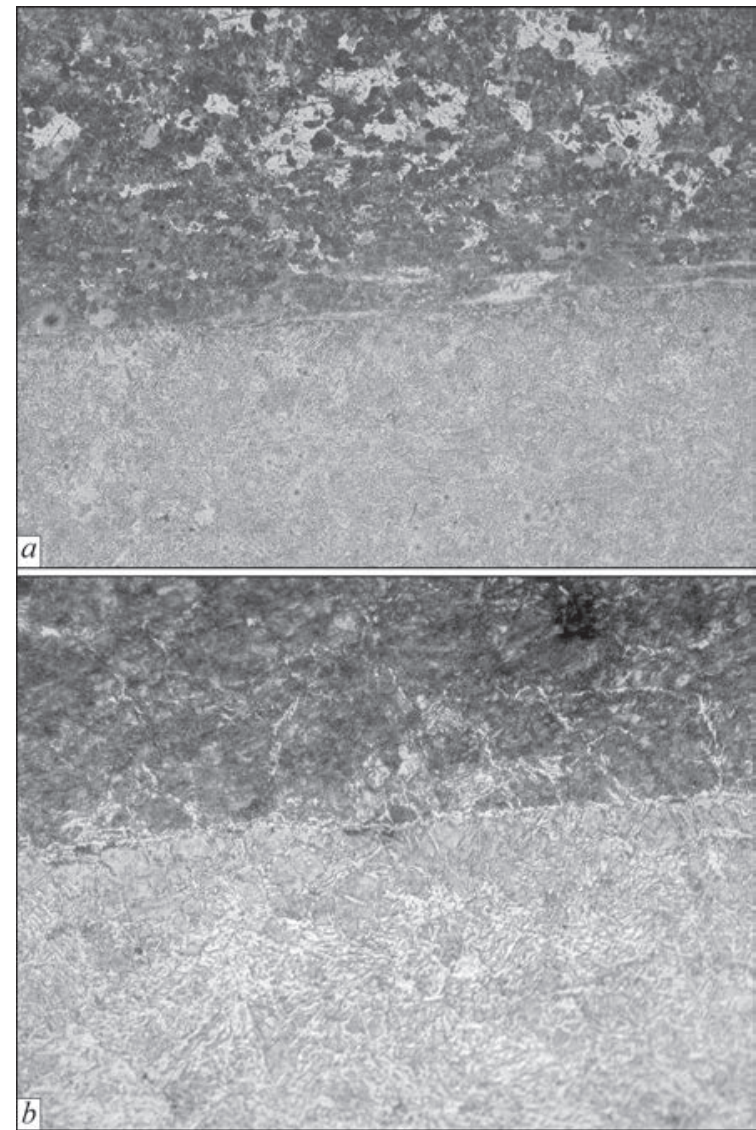

Figure 10. Microstructure of metal of peripheral area III: $a-$ $\times 100 ; b-\times 400$

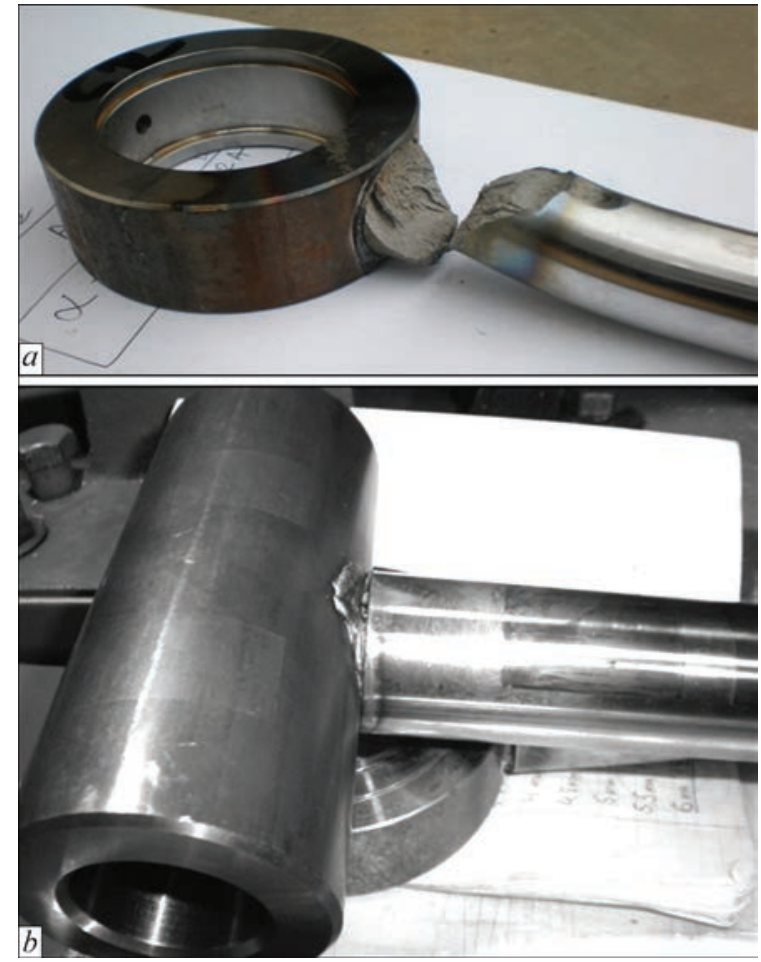

Figure 11. Rod Sh25 RB-welded according to scheme 1 after tests on bending $(a)$, and rod produced according to scheme $2(b)$ (see Figures 1 and 3, respectively) 


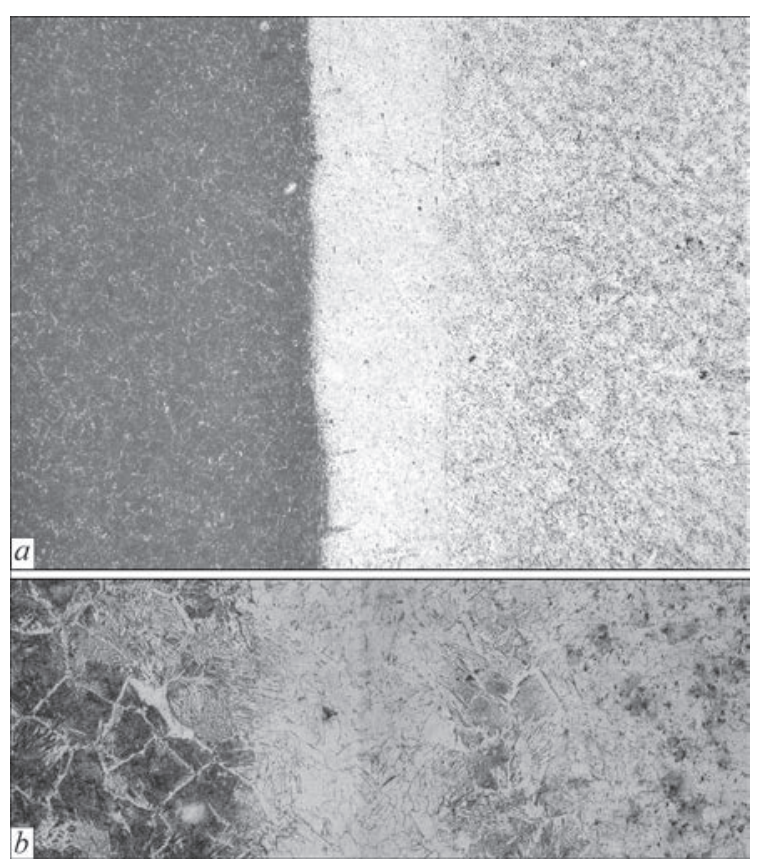

Figure 12. Microstructure of metal in cross-section center in RBW according to scheme $2: a-\times 50 ; b-\times 200$

of metal in different zones of the joint is presented in Figures 12 and 13, the distribution of microhardness of metal in the joining area - in Figure 14. During metallographic examinations in the joining area none of the defects (cracks, lacks of penetration, pores, oxide films, remnants of flux) are detected. In order to prevent the formation of hardening structures while
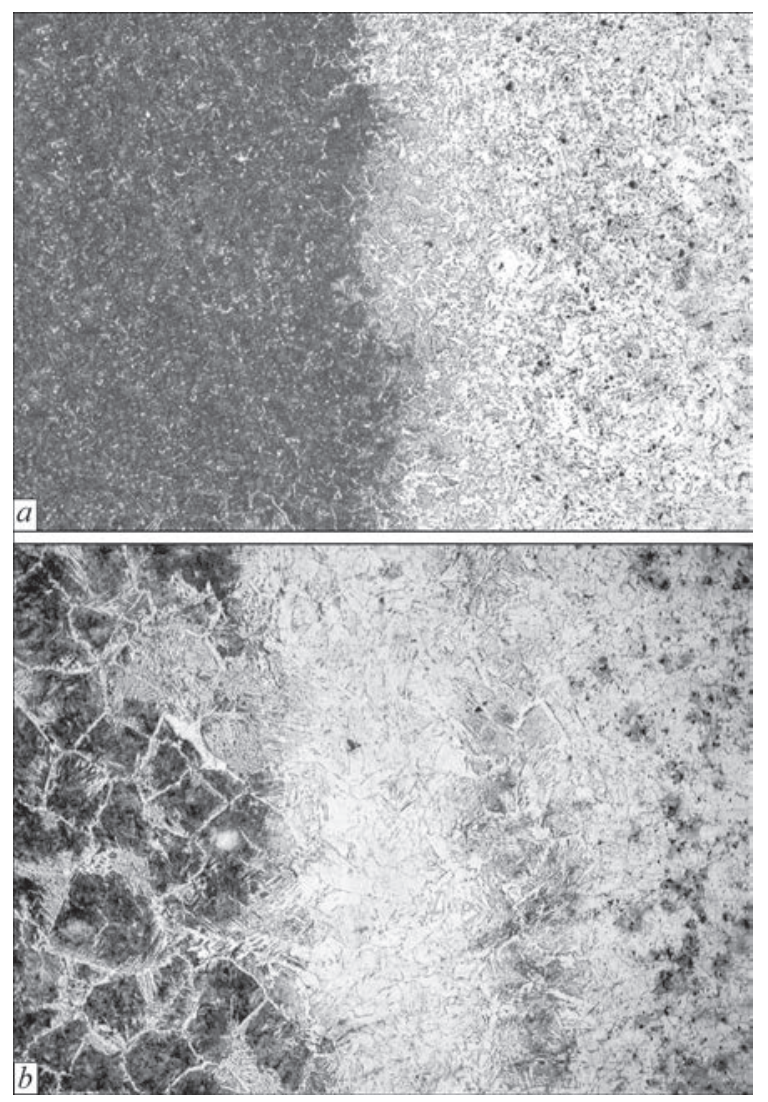

Figure 13. Microstructure of metal in cross-section periphery in RBW according to scheme $2: a-\times 50 ; b-\times 200$

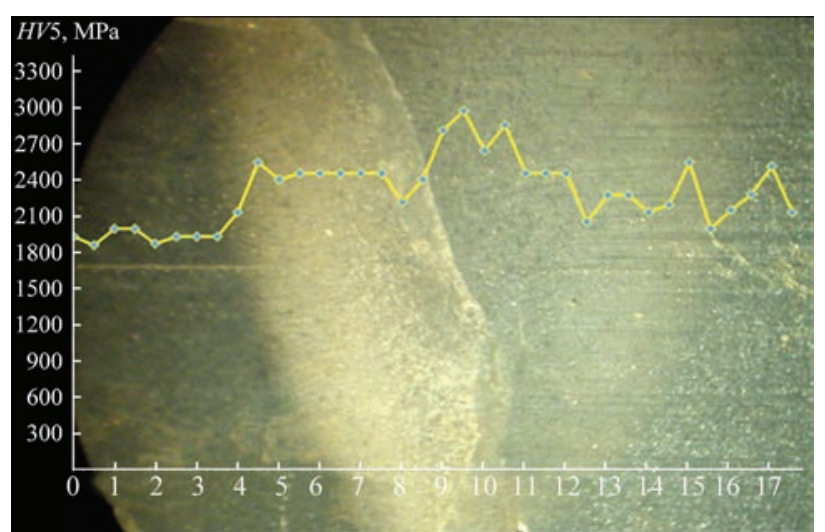

Figure 14. Distribution of microhardness in the area of welded joint after heat treatment in clamps of welding machine

joining the rods of large diameter (more than $32 \mathrm{~mm}$ ) the postweld heat treatment of rods in the clamps of the welding machine was carried out by passing the current pulses and at the same time the pyrometric control of heating temperature was carried out.

On the basis of investigation results the technology of RBW of rods of hydraulic cylinders of steels 45 and 17GS of diameter from 16 to $60 \mathrm{~mm}$ was developed. The technology was realized in specialized welding machine K1040 with welding force from 600 to $7200 \mathrm{~kg}$, at welding current from 15 to $65 \mathrm{kA}$ during joining the rods of different types and sizes, and welding time from 0.8 to $3.5 \mathrm{~s}$.

For the first time for welding machines of such power the three-phase frequency converter was applied, which provides a uniform loading of phases. RBW with postweld heat treatment in the clamps of the machine provides the strength of welded joint of rod and eyelet of hydraulic cylinder at the level of the rod base metal. The welding modes for 96 variants of joints of rods and eyelets were developed. As a result of experiments, the parameters of preliminary edge preparation of different sizes of rod and eyelet were optimized. At the developed technology for RBW of rods in the range of diameters of 16-60 mm the quality joint formation without splashes, with high mechani-

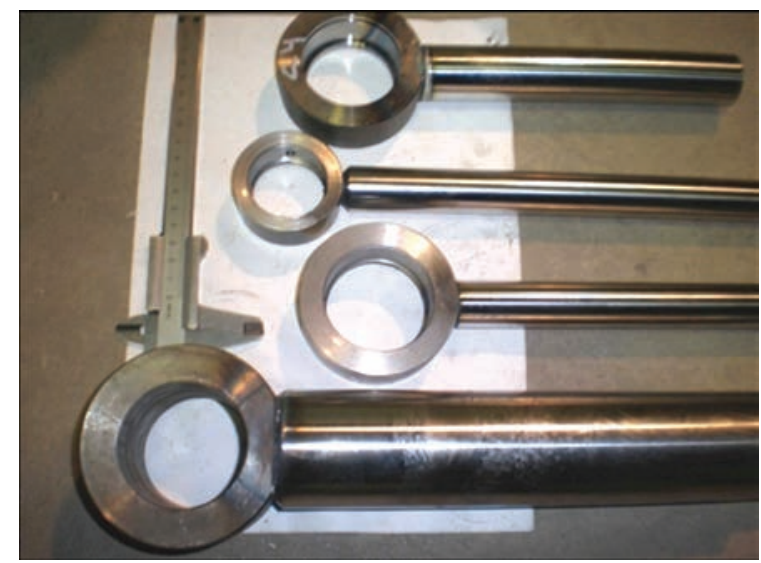

Figure 15. RB-welded rods 
cal properties and high geometry precision of welded product is provided, the allowance for the length and diameter does not exceed $0.5 \mathrm{~mm}$ (Figure 15). The hydraulic cylinders with rods, welded according to the developed RBW technology, successfully passed the certification tests and are supplied to the EU countries, countries of Eastern Europe and Iran.

\section{Conclusions}

In RBW of large-section T-joints the formation of quality joints is complicated due to asymmetry of heating and deformation conditions, which causes the formation of defects and low values of static and cyclic strength.

It was found that in RBW with optimal preparation of welded edges and programmable change in welding force at the heating stage it becomes possible to localize heat generation in the zone of welding rods to egelets in the investigated range of diameters (up to $60 \mathrm{~mm}$ ), to avoid the defects formation and to provide high mechanical properties of welded joints.

Metallographic examinations revealed that lacks of penetration, oxide films, cracks, caused by the formation of hardening structures, are absent in the joints. The metal structure in the joint zone and the zone of thermomechanical influence is ferrite-pearlite, the areas with martensite structure were not detected. During mechanical tests of welded rods on bending the fracture occurs over the base metal of the rod.

The technology of RBW of T-joints of dissimilar steels 45 and 17GS using the composite inserts was developed.

The technology for RBW of rods of hydraulic cylinders with diameter of $16-60 \mathrm{~mm}$ was realized in specialized welding machine K1040, designed and manufactured at the PWI. It uses a three-phase frequency converter, which provides a uniform loading of phases. The welded cylinders successfully passed the certification tests.

1. Sakhatsky, G.P. (1963) Investigation of flash-butt and resistance welding. Avtomatich. Svarka, 10, 26-32.

2. Lebedev, V.K., Besprozvanny, I.A., Mirgorod, Yu.A. (1979) Resistance butt welding and inertia friction welding of billets of end metal-cutting tools. Ibid., 8, 39-43.

3. Zhang, H., Senkara, J. (2006) Resistance welding fundamentals and applications. Boca Raton.

4. Kuchuk-Yatsenko, V.S., Shvets, V.I., Sakhatsky, A.G. et al. (2007) Peculiarities of resistance welding of aluminium alloys using nanostructural and aluminium-nickel and aluminium-copper foils. Svarochn. Proizvodstvo, 9, 12-14.

5. Kuchuk-Yatsenko, V.S., Shvets, V.I., Sakhatsky, A.G. et al. (2009) Features of resistance welding of titanium aluminides using nanolayered aluminium-titanium foils. The Paton Welding J., 3, 11-14.

6. Kuchuk-Yatsenko, S.I., Zyakhor, I.V., Chernobaj, S.V. et al. (2015) Structure of $\gamma$-TiAl joints in resistance butt welding with application of interlayers. Ibid., 9, 5-12.

7. Kharchenko, G.K., Novomlynets, O.O., Fedorchuk, V.E. et al. (2007) Weldability of new alloys of Al-Cr-Fe-Ti system hardened with nanoquasicrystal particles. Visnyk ChernigivDTU, 30, 55-60.

8. Kuchuk-Yatsenko, S.I., Kharchenko, G.K., Zagadarchuk, V.F. et al. (2004) Formation of structure of joints in resistance and flash-butt welding. The Paton Welding J., 2, 13-16.

9. Kuchuk-Yatsenko, S.I., Rudenko, P.M., Gavrish, V.S. et al. (2015) Converter of frequency and number of phases for flash-butt welding of rails. Ibid., 7, 38-40.

10. Kuchuk-Yatsenko, V.S., Nakonechnyi, A.A., Sakhatskiy, A.G. Method of resistance butt welding corrugated flux-filled metal inserts. Pat. 8,426,762, B2 US. Publ. 23 April, 2013.

11. Song, Q., Zhang, W., Bay, N. (2005) An experimental study determines the electrical contact resistance in resistance welding. Welding J., 85(5), 73-76.

12. Kuchuk-Yatsenko, V.S., Nakonechny, A.A., Gavrish, V.S. et al. (2012) Technology of projection welding of parts of large thicknesses with T-shaped joints. The Paton Welding J., 8, 42-44.

13. Lipa, M., Golasek, Ya. (1970) Resistance projecion welding. Kiev: Tekhnika.

14. Gilevich, V.A. (1976) Technology and equipment for projection welding. Leningrad: Mashinostroenie. 